\title{
Novel use of overtube for rectal foreign body to "clean" out the colon: Extraction of large Tide-To-Go pen
}

\author{
Paul P Shao*1,2, Winston Yen ${ }^{3}$, Jasleen K. Grewal ${ }^{1,2}$, Ryan Perumpail ${ }^{1,2}$, Felix Leung ${ }^{1,2}$ \\ ${ }^{1}$ David Geffen School of Medicine at UCLA, Los Angeles, California, USA \\ ${ }^{2}$ Greater Los Angeles Veterans Affair Health Care System, Los Angeles, California, USA \\ ${ }^{3}$ Touro College of Osteopathic Medicine, Harlem, New York, USA
}

Received: October 22, 2020

DOI: $10.5430 /$ dcc.v7n3p20
Accepted: December 31, 2020 Online Published: January 7, 2021

URL: https://doi.org/10.5430/dcc.v7n3p20

\begin{abstract}
The rate of colorectal foreign bodies is increasing. Endoscopists must be creative in order to remove the foreign objects safely in the most minimally invasive manner as these objects could vary greatly in size and shape. We present a case of the novel use of an esophageal overtube to aid in the removal of a difficult-to-remove Tide-To-Go cap.
\end{abstract}

Key Words: Rectal foreign body, Colonoscopy, Extraction, Rectum

\section{INTRODUCTION}

The rate of colorectal foreign bodies is rising. ${ }^{[1]}$ This poses an interesting challenge to endoscopists as there is great variability in object size, shape, and surface characteristics. ${ }^{[2,3]}$ This heterogeneity requires endoscopists to have a diverse range of techniques at their disposal to safely remove colorectal foreign bodies in a minimally invasive manner. We present a case of the novel use of an esophageal overtube to aid in the removal of a difficult-to-remove Tide-To-Go cap.

\section{CASE REPORT}

The patient was a 55-year-old male with no past medical history who presented to the emergency department 24 hours after inserting a smooth plastic Tide-To-go pen into his rectum. When he attempted to remove the pen, the cap was left behind. He denied any pain, hematochezia, fevers or chills. His vitals were normal. Complete blood count and metabolic panel were unremarkable. He underwent a CT scan which showed a well circumscribed air-containing elongated and cone-like region occupying the rectum and rectosigmoid with mild thickening of the rectal wall without extraluminal air. We initially gave him 4 liters of Golytely to flush the object, but he did not pass the object on his own. We could not visualize the object on the visual exam. Digital rectal exam failed to palpate the object. Patient therefore underwent flexible sigmoidoscopy for foreign object extraction. During flexible sigmoidoscopy, we could appreciate a very strictured and erythematous rectum (see Figure 1) and a smooth, white, plastic object lodged in the rectosigmoid colon. Multiple attempts at pulling the object out with rat-tooth forceps, snare, and Roth net were all futile as we could not pull the object through the narrowed rectum. We then inserted a heavily lubricated esophageal overtube through the rectum and pulled the object into the overtube and removed the cap and overtube together (see Figures 2-3). The overtube helped dilate and straighten the rectum while allowing the object to be secured into the overtube. USA. 
After discussing the stricturing noted in the rectum with the patient, he revealed that he had previously inserted approximately 20 different objects requiring repeat interventions for removal. We counseled him extensively on the risk of perforation and he stated that he understood and that he was ready to put colorectal foreign bodies behind him.

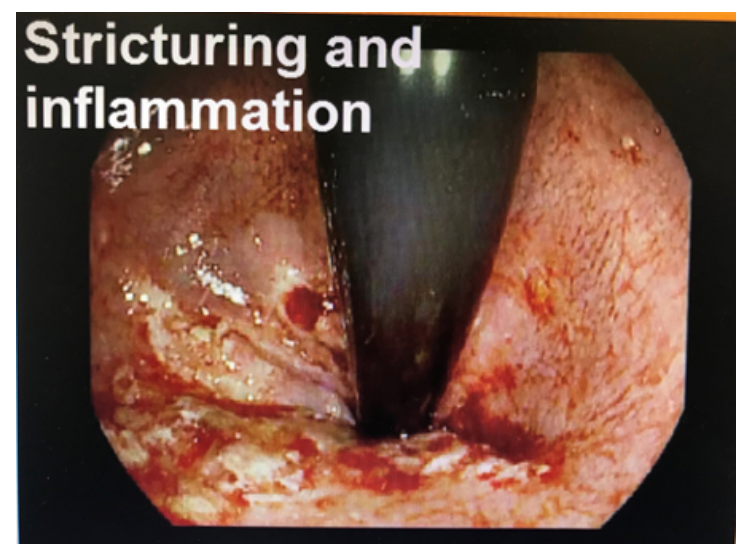

Figure 1. Friable rectal mucosa with stricturing and inflammation

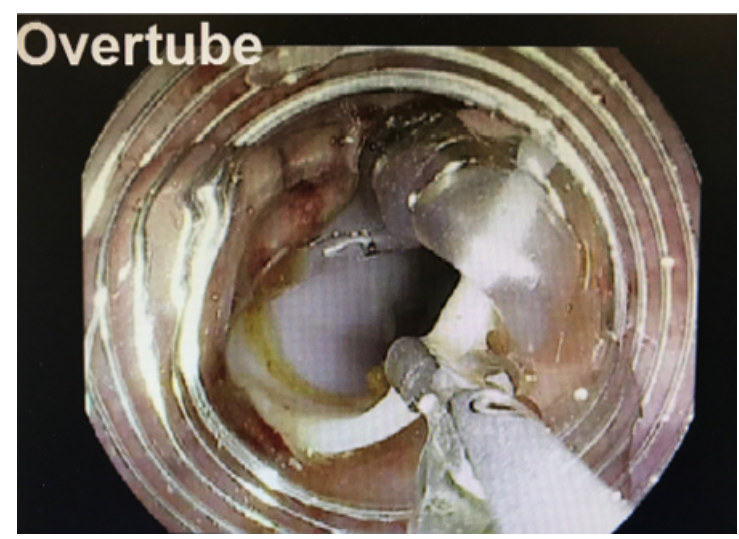

Figure 2. Pulling the foreign object into the overtube

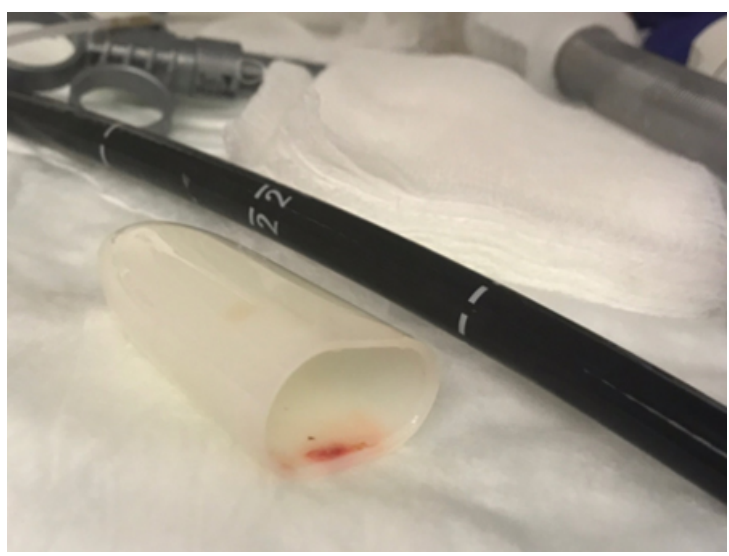

Figure 3. Plastic Tide-To-Go cap removed

\section{Discussion}

The incidence of patients presenting to emergency departments with rectal foreign bodies is increasing, particularly in males (Dahlberg). The majority of cases involve purposeful insertion of household objects, sex paraphernalia, food items etc. for sexual stimulation and self-gratification. ${ }^{[4-6]}$ A metanalysis reported that sexual devices $(35.7 \%)$ were the most commonly used item, followed by glass bottles (17.5\%) for rectal insertion. The study found a $6: 1$ ratio $(86.1 \%)$ of men to women with an age range of 11 to 80 years. ${ }^{[4]}$ Due to the nature of these cases, patients may be reluctant to provide an accurate history, conceal their injuries, delay evaluation, and make attempts of self-retrieval, which may result in further complication. Challenges to extraction include the variability in size, shape, and flexibility of the foreign body as well as the local anatomy of the GI tract in which the object is found. Although a systematic approach is used to manage these patients, conventional methods are often unsuccessful and may cause further harm. ${ }^{[7,8]}$

Initial evaluation of rectal foreign body includes ruling out peritonitis as perforation of the rectum or sigmoid colon requires emergent laparotomy. ${ }^{[9]}$ A digital rectal examination should be performed to determine the distance of the rectal foreign body from the anal verge and to evaluate sphincter competency. An abdominal series with X-ray or CT abdomen and pelvis can identify the size, shape, and location of the foreign body and exclude pneumoperitoneum if peritonitis is suspected. ${ }^{[10]}$ Once the preliminary assessment rules out peritonitis, manual extraction of the rectal foreign body should follow if the object is palpable on digital rectal exam. Bedside extraction can be attempted after local anaesthesia with or without sedation as the trans-anal approach is least invasive and has a $60 \%$ to $75 \%$ success rate. ${ }^{[9,10]}$ After dilation of the anal canal, attempts can be made to extract the object, either by-hand or with the aid of tools.

If bedside extraction through the trans-anal route is unsuccessful or if the object is deemed too high for manual approach, an endoscopy procedure may be performed to visualize the object and tools such as polypectomy snare, or forceps can be used for the extraction. ${ }^{[7,9]}$ Endoscopic instruments allow for precise contact and removal of the foreign body while reducing chances of iatrogenic injury. Of interest, Tenaculum forceps used in obstetrics have demonstrated utility in grasping objects during endoscopy guided procedures due to its sharp hooks on the end of each jaw. ${ }^{[1]}$ Additionally, the use of air insufflation during the procedure can raise intraluminal pressure and allow for loosening of the foreign body. ${ }^{[5,8]}$ In cases where the lumen is narrowed, air insufflation helps distend the bowel wall which aids in both visualization and extraction. ${ }^{[8]}$ 
Despite standard protocol, disparities in location and physical properties of the foreign object present unique challenges during retrieval. The acute angle of the rectosigmoid junction can often hinder extraction efforts, especially when the object is inflexible. ${ }^{[12]}$ Furthermore, recurrent episodes of rectal foreign body insertion requiring repeat endoscopic and surgical interventions for extraction can lead to anorectal stricturing, mucosal edema, sphincter spasm, rectal anteflexion, and atony. ${ }^{[4]}$ The alteration of anatomy may, as in this case, result in difficulty with foreign body extraction despite endoscopic access to the object. After several attempts at manual extraction, including the use of rat-tooth forceps, snares, and Roth net, we were unable to remove the Tide-to-go pen cap. Stenting of the overlying mucosa and straightening of the rectum with an esophageal overtube facilitated successful retrieval by reducing the angle of the rectosigmoid junction. This produced the dilation and straightening of the rectum necessary to access and dislodge the cap with its subsequent removal in the overtube without complication. Therefore, the application of an overtube for future management of rectal foreign bodies in the rectosigmoid colon with stricturing should be considered. The use of overtube to stent and straighten the rectum can be an effective, low-cost method in extracting rectal foreign body. To our knowledge, this is the first reported experience of overtube-guided rectal foreign body extraction in the United States. Prior reports from Korea and Portugal also highlighted the utility of this approach. ${ }^{[12,13]}$

\section{CONFLicts OF InTEREST Disclosure}

The authors declare they have no conflicts of interest.

\section{REFERENCES}

[1] Kurer MA, Davey C, Khan S, et al. Colorectal foreign bodies: a systematic review. Colorectal Disease. 2010; 12(9): 851-861. PMid:19895597.https://doi.org/10.1111/j.1463-1318. 20 $09.02109 . \mathrm{x}$

[2] Sei H, Tomita T, Nakai K, et al. Rectal Foreign Body of Eggplant Treated Successfully by Endoscopic Transanal Removal. Case Rep Gastroenterol. 2018; 12(1): 189-193. PMid:29805365. https : //doi.org/10.1159/000488974

[3] Coskun A, Nazif E, Savas Y, et al. Management of rectal foreign bodies. World Journal of Emergency Surgery. 2013; 8(1): 1-5. PMid:23497492. https ://doi.org/10.1186/1749-7922-8-1 1

[4] Ploner M, Gardetto A, Ploner F, et al. Foreign rectal body-Systematic review and meta-analysis. Acta gastro-enterologica Belgica. 2020; 83(1): 61-65.

[5] Mikami H, Ishimura N, Oka A, et al. Successful transanal removal of a rectal foreign body by abdominal compression under endoscopic and X-ray fluoroscopic observation: a case report. Case Reports in Gastroenterology. 2016; 10(3): 646-652. PMid:27920656. https://doi.org/10.1159/000452210

[6] Dahlberg M, Nordberg M, Pieniowski E, et al. Retained sex toys: an increasing and possibly preventable medical condition. International Journal of Colorectal Disease. 2019; 34(1): 181183. PMid:30030606. https : //doi.org/10.1007/s00384-018 $-3125-4$

[7] Goldberg JE, Steele SR. Rectal foreign bodies. Surgical Clinics. 2010; 90(1): 173-184. PMid:20109641. https://doi.org/10.1016/j . suc. 2009.10 .004

[8] Koornstra JJ, Weersma RK. Management of rectal foreign bodies: description of a new technique and clinical practice guidelines. World journal of gastroenterology: WJG. 2008; 14(27): 4403. PMid:18666334. https://doi.org/10.3748/wjg.14.4403

[9] Cologne KG, Ault GT. Rectal foreign bodies: what is the current standard? Clinics in Colon and Rectal Surgery. 2012; 25(4): 214. PMid:24294123. https://doi .org/10.1055/s-0032-132 9392

[10] Kasotakis G, Roediger L, Mittal S. Rectal foreign bodies: A case report and review of the literature. International Journal of Surgery Case Reports. 2012; 3(3): 111-115. PMid:22288061. https://doi. org/10.1016/j.ijscr.2011.11.007

[11] Lim KJ, Kim JS, Kim BG, et al. Removal of rectal foreign bodies using tenaculum forceps under endoscopic assistance. Intestinal Research. 2015; 13(4): 355. PMid:26576143. https://doi.org/10 .5217 /ir.2015.13.4.355

[12] Silva M, Albuquerque A, Ribeiro A, et al. Overtube-guided endoscopic extraction of a rectal foreign body: lifting not only the embargo. Endoscopy. 2015; 47(Suppl 1): E563-4. https : //doi .org/ $10.1055 / \mathrm{s}-0034-1393392$

[13] Park Sa, Keum B, Jeen YT. Stercoral ulcer due to chicken bones in rectum: overtube used as a conduit for endoscopic removal. Clinical Gastroenterology and Hepatology. 2010; 8(3): A32. PMid:19500690. https://doi.org/10.1016/j.cgh.2009.05.022 